\title{
Delusion Side of Arthur Fleck as the Main Character in Joker Movie by Todd Philips'
}

\author{
Betty Susanti HS ${ }^{1 *)}$, Tahrun ${ }^{1}$, Mulyadi ${ }^{1}$
}

\author{
${ }^{1}$ Universitas PGRI Palembang \\ *Corresponding author.Email: beebetty.better@gmail.com
}

\begin{abstract}
As A movie Character Arthur Fleck, also known as Joker, is represented as a boy with a neglectful mother and a father figure's absence. He has characteristics as a cruel killer suffering from mental illness, with a clown-like look, spreading fear and terror in Gotham city. Using descriptive analysis, psychoanalytical, and delusion Munro theory focusing on Fleck as the main character in this movie, this paper tries to see what kind of delusion and treatment is found in the movie. Based on the analysis, it is revealed that Fleck has a dynamic character. While he is depicted as a heartless killer, his delusion side is specifically revealed in certain elements.
\end{abstract}

Keywords: Joker, Psychoanalytical, Delusion and Treatment, Dynamic Character

\section{INTRODUCTION}

A Movie, as a result of popular culture, reflects the daily life of people, in reality, brings an almost complete facet of social reality into all aspects of individual and collective lives. The film's dynamism is built upon its ability to record and re-arrange time and motion [1]. It, therefore, reveals its different aspects, which are profoundly political, psychological, metaphysical, aesthetic, personal, industrial, technological, etc. The movie cannot be isolated from literature either. Movies are a semi-textual genre, subject to literature and literary criticism by both and results [2]. But the tradition is also influenced by literary techniques; rather, literary ability developed under specific characteristics by the effects of a film. Then he added, while movies have their own particular characteristics and terminology, they can be studied using literary critical methods, as they have an important link with conventional approaches to textual studies. Nancy Kaplan, as quoted by, stated that in the past, literature was closely linked to printing technology, while in modern times, literature is not only textual, but also visual, electronic, non-verbal, and gestural. Therefore, a film can be said as an object of literary studies.

Character behavior is one of the psychological phenomena shown in the literature [3]. We use language in writing literature, such as essays, poetry, novels, or other imagination works. The film is a technology that provides entertainment, thus making a person gain experience [1]. Films are an important, popular, and even powerful way to educate. So, the film is a form of technological drama that originates from the narrative text of literary works

Film or Movie has genres, one of which is Psychological Thriller. There have been many Psychological Thriller genre movies seen from the narrative where the action is suppressed and the sensation given through the main character's psychological investigation is tamed. The distinguishing characteristic of psychological thrillers is the marked emphasis on the mental states of their characters, such as their thoughts, distortions, perceptions, and struggles to make sense of reality.

Education was one of the efforts to stimulate, coordinate, and guide the teachers' continuous growth in school, both individually and collectively. Education has a system that is more comprehensive and effective in carrying out all the teaching functions so that they can continuously stimulate and guide the growth of each student and be able and more capable of participating in modern democratic society. Psychology is a scientific study of a person's thoughts and behavior. Nowadays, psychology is a popular subject for students in the public media and is part of our daily lives [4]. 
As for literary psychology, delusion is a psychological disorder, in which the sufferer has false beliefs that are not related to reality. These beliefs are not associated with that person's culture or religion. If you believe in Voodooist, delusion is a state of being possessed by spirits. These circumstances must be accepted and respected. However, according to social views, delusions are seen as delusions [5].

The psychological approach in analyzing and studying literature is carried out by experts using certain methods. Psychoanalysis can be described as psychological technology and psychology school about identity as a psychology stream, especially in terms of structure, dynamics, and creation [6]. Psychological intervention is an approach or criticism of literary works related to one's mental state as a key subject to discuss [7].

The psychological approach can concentrate on three aspects: experts, books, and the consumer. The psychological methodology used to analyze the author suggests that the author's psychological component should be evaluated. The role examined using physiological means is to review the mental factors of the characters in the work. In evaluating the reader, the last psychological approach means analyzing the reader's psychological element after reading a literary document.

Psychology literary approach should be seen from psychology's perspective as a tool to study and draw the idea that literature often discusses events in human life that appear in life [7]. The role of psychology itself in this supplement, through conversation through the inner psyche of people and learning the nuances of activity. By using a psychological approach in analyzing literary works, we can know that literary works should know the events and circumstances in the literary work and know what feelings are shown and expressed by the characters in the literary work. In the Joker movie, the writer focuses on the characters' psychological aspects, namely the delusions faced by characters in literary works.

A psychological disorder is an ongoing dysfunctional pattern of thought, emotion, and behavior that causes significant distress and that is considered deviant in that person's culture or society [7]. Delusion is a form of a serious mental illness, "Psychosis," where a person may not tell anything real from what is imagined to." She identified several theorists according to the illustration above which gave a claim for deception. Due to a lack of other moods, the delusional condition is a disease, such as a sensation or mental symptoms causes [8]. Individuals with delusional disorders encountered unusual gifts that may emerge with true causes, such as pursued, ravaged, deluded, combated with, or lost away to accept their individuals. Such delusions often include an erroneous perception of views or experiences. Ultimately, however, the circumstances are either not important in order or exaggerated very badly [8].
A psychological disorder is an ongoing dysfunctional pattern of thought, emotion, and behaviour that causes significant distress and that is considered deviant in that person's culture or society [5]. Some types of delusional disorder are described below: erotomanic type, grandiose type, jealous type, persecutory type, and somatic type [8]. Perception illness could be an ingenious idea because they thought it was unlikely, and the others thought it was not. According to some observations explained below, the writer may assume that a distinct reference is made in these three representations above about a deceitful condition, but only one indicator is that the author knows the illusory condition is an accident of mental illness. There are skewed perceptions and thought under psychotic disorders.

\section{METHODS}

This study uses a qualitative descriptive method to explain the illusions in the "joker" film. Data in this study was collected in words or pictures instead of numbers [9].

\section{RESULTS AND DISCUSSION}

The types of information collected in qualitative research included notes, field statements, photos, sound recordings, videocassettes, graphics, articles, personal comments, emblems, official statements, textbook lyrics, and all those that could express people's real acts or phrases. Qualitative researchers tend to analyze their inductions. Before entering the analysis, they do not show data or facts to prove their conclusions, but the abstractions are constructed as data is collected together.

The scope of this research included pictures and dialogs that have to be checked. The bibliography work is the best attempt to gather the details. Supporting data is obtained from various sources, including libraries or study rooms. The authors attempt to read studies on the subject chosen by the researcher. The research framework concentrates on reviewing the documentation that has been influenced by the use of multiple written sources to facilitate the learning of the study.

The analysis utilizes the source for knowledge from the Joker film. Meanwhile, the data from this research were kinds of lusting, comments and disclaimers heard by the produced in the Joker movie. In addition, further sources of data, including references and study related materials from books, journals or the Internet, were obtained from the researcher.

This studies indirectly discuss, concentrate and gathered from other sources. The data source was needed for the support and exit of the primary data. The knowledge was used in all studies related to books for the movie, including books on the theory of psychological 
disruption and fraud. The writer gathers from websites information about this study paper for more information.

Triangulation refers to (at least) two separate views on the basis of the analysis of a research issue; Triangulation has been applied as a qualitative review method for assessment inquiry by incorporating data from various sources. Triangulator to integrate data sources with testing methods, theoretical viewpoints and inspectors for analyzing, screening, examination of behavioral specimens with the study techniques, and other methods for. The writer applied the technique of triangulation to improve the accuracy of the report. This included three various types in the collection of data.

Several factors found why Arthur Fleck in the Joker film experienced a psychological disorder. First, Arthur Fleck's mother had a psychological breakdown and brainwashed her son by saying that Arthur was the son of Thomas Wayne. Second, his desire to become a famous comedian but gets a lot of bullying. Finally, he lost his job as a clown and drugs to relieve symptoms of delusional delusions from government assistance that made matters worse. These factors significantly affect a person's attitude, behavior, and mentality [11].

\section{CONCLUSION}

Fleck has a dynamic character and his delusion side is specifically revealed in certain elements. So, movie turns out to be an important thing in learning especially in learning English. Many people including students, parents, and teachers benefit from movie itself. The learning process becomes easier and more enjoyable because the movie method comes out in learning method. One of the benefit of using psychoanalytic we can be a good analyser of the characterization in movie also knowing of delusion suffered by the main character in the movie.

\section{REFERENCES}

[1] Villarejo, A. (2007). Films studies The Basics. New York: Routledge Taylor and Francis Group.

[2] Kelder, R. (1996). Rethinking Literacy Studies: From the Past to the Present. Thirty-three selected papers from this conference are available on the.

[3] Jatman, D. (1998). Sastra, Psikologi, danMasyarakat. Bandung: Alumni.

[4] Hutchings, P. (2009). The A to $Z$ of Horror. Scarecrow Press. p. 253. ISBN 9780810870505.

[5] Dujaily, A. (2009). Delusional Disorder. Retrieved from http://www.mindclinics.org/library/files/pdf/delusio naldisorder.pdf.Accessed on September 16 ${ }^{\text {th }}, 2014$.
[6] Freud, S. (2012). The basic writings of Sigmund Freud. Modern library.

[7] Stangor, C. (2009). Principle of social Psychology $1^{\text {st }}$ International edition. Open.BCCAMPUS.CA.

[8] Munro A. (1999). Delusional disorder: paranoia and related illnesses. Cambridge (UK): Cambridge University Press

[9] Harjana, S. (2011). Teori, Metode, danTeknik Penelitian Sastra. Yogyakarta: Pustaka Pelajar.

[10] Butcher, J., Mineka, S., \& Hooley, J. (2007). Abnormal psychology and modern life $\left(13^{\text {th }} \mathrm{ed}\right.$.). Boston, MA: Allyn\& Bacon.

[11]Bandura, A. (2009). Media Psychology: Social Cognitive and Mass Communication. London: Routledge. 